\section{Vigilancia epidemiológica incompleta de la epidemia de dengue-2 en lbagué, Colombia, 1995-1997}

\author{
Fredi Alexander Díaz
}

Centro de Investigaciones Epidemiológicas, Facultad de Salud, Universidad Industrial de Santander, Carrera 32 N $^{\circ}$ 29-31, tercer piso, Bucaramanga, Colombia.

Telefax: 6345781

frediazq@msn.com

En la publicación sobre la vigilancia epidemiológica del dengue, T. Camacho et al. reportaron 3.419 casos sospechosos notificados en los años 1995 a 1997 en Ibagué. Entre éstos, se practicaron pruebas de anticuerpos IgM en 2.580 , de los cuales, 1.977 fueron positivos. Los autores consideran casos confirmados de dengue, aquellos clínicamente sospechosos con una prueba de IgM positiva (1).

Es importante señalar que la actual definición de un caso confirmado de dengue, según la recomendación de la OMS (2), debe incluir, al menos, uno de los siguientes criterios:

1) aislamiento del virus del dengue del suero, el plasma, los leucocitos o muestras de la autopsia;

2) aumento de cuatro veces o más de los títulos recíprocos de anticuerpos IgG o IgM contra uno o varios antígenos del virus del dengue en muestras séricas pareadas;

3) detección del antígeno del virus del dengue en el tejido de la autopsia o en muestras séricas por EIA;

4) detección de secuencias genómicas víricas en el tejido de la autopsia, el suero o muestras de líquido cefalorraquídeo por reacción en cadena de polimerasa.

Los casos reportados por los autores, con una sola IgM positiva para dengue, deben considerarse como "probables", categoría en la que también se incluyen aquéllos clínicamente sospechosos que aparecen en el mismo lugar y al mismo tiempo que otros casos confirmados de dengue (2).

La necesidad de una segunda muestra de suero para confirmar el diagnóstico se basa en que los anticuerpos IgM pueden ser detectables, en promedio, hasta 2 meses después de una infección, la cual puede ser asintomática (3). Durante este periodo otra enfermedad febril similar al dengue podría ser generada por otros patógenos emergentes, los cuales podrían ser subregistrados $(4,5)$.

Por otra parte, la ausencia de anticuerpos en una muestra tomada en los primeros días del inicio de los síntomas no descarta la infección por el dengue debido a que sólo después del día sexto de enfermedad, la sensibilidad de las pruebas disponibles es mayor al $90 \%$ (3).

Los anteriores argumentos resaltan la importancia de una segunda muestra de suero en la convalecencia y la utilidad de técnicas como el aislamiento viral en la fase aguda de la enfermedad, en la documentación adecuada de los casos de dengue y en la vigilancia de otros patógenos causantes de síndrome febril agudo.

\section{Referencias}

1. Camacho T, de la Hoz F, Cárdenas V, Sánchez C, de Calderón L, Pérez L et al. Incomplete surveillance of a dengue-2 epidemic in Ibagué, Colombia, 1995-1997. Biomédica 2004;24:174-82.

2. Organización Panamericana de la Salud. Definiciones de casos. Dengue. Boletín Epidemiológico 2000;21:14-5.

3. Rigau-Pérez JG, Clark GG, Gubler DJ, Reiter P, Sanders EJ, Vorndam AV. Dengue and dengue haemorrhagic fever. Lancet 1998;352 971-7.

4. Instituto Nacional de Salud de Colombia. Epidemia de influenza A/H3N2/Beijing/32/92 en Ambalema, Tolima, 1994. Inf Quinc Epidemiol Nac 1996;1:6-8.

5. Tauil PL. Urbanizacao e ecologia do dengue. Cad Saude Publica 2001;17:99-102. 


\section{Respuesta}

El doctor Díaz se refiere al artículo Incomplete surveillance of dengue 2 epidemic in Ibagué Colombia, 1995-1997 (1) y cuestiona la definición de caso de dengue utilizada en ese estudio y para ello se basa en la definición de caso de dengue promulgada por la Organización Mundial de la Salud en el 2000 (2).

En primer lugar, es necesario aclarar que dicho estudio se llevó a cabo en 1998, cuando la mencionada definición no estaba disponible; en segundo lugar, debo resaltar que la definición usada en ese estudio era la misma que usaba la mayoría de las secretarías de salud del país porque estaba de acuerdo con las recomendaciones que, para entonces, había formulado el Ministerio de Salud.

Aunque desde el punto de vista clínico y virológico es cierto que para confirmar un caso individual de dengue se requerirían, al menos, uno de los criterios citados por el doctor Díaz, no lo es menos que, desde el punto de vista de la población, la ausencia de esos criterios del 2000 en nuestro artículo no afecta la validez de nuestra afirmación de que en el período descrito hubo circulación continua del virus dengue en Ibagué. Ello se corrobora por los aislamientos virales durante el período y por el mismo hecho de que la vigilancia en salud pública haya encontrado prevalencias muy altas de positividad a títulos de IgM antidengue entre los febriles que consultaron a los sitios de vigilancia. Es poco probable que una prevalencia de $77 \%$ de IgM en pacientes febriles no coincida con un período de circulación importante del virus si, como lo afirma el mismo doctor Díaz, los anticuerpos IgM sólo están positivos por 2 meses después de la infección. Además, en las Guías para la prevención y el control del dengue de la Organización Panamericana de la Salud se reconoce la necesidad de notificar, a las autoridades nacionales, los casos "probables" como casos de dengue por lo cual la división entre "probables" y "confirmados" es poco práctica en la realidad cotidiana de la vigilancia en salud pública.

Aunque la recomendación de tomar una segunda muestra durante la convalecencia es válida, su aplicación en la práctica es difícil como fácilmente puede evidenciarse al revisar las fichas clínicas de dengue de cualquier servicio de salud en las cuales la gran mayoría de los pacientes tiene una sola muestra y donde las limitaciones logísticas y de personal para la vigilancia hacen que sea prácticamente imposible obtener una segunda muestra. Por lo tanto, es necesario recomendar para la vigilancia de la población, hacer más énfasis en el fortalecimiento de la vigilancia centinela sobre la circulación del virus que, finalmente, es lo que nos puede demostrar sin ambajes, la circulación del virus.

En realidad los comentarios del doctor Díaz coinciden con nuestro artículo en la necesidad de mejorar la vigilancia de las enfermedades febriles en el país ya que, actualmente, el único diagnóstico que se hace sistemáticamente por laboratorio es el de dengue y no existe capacidad, excepto en algunos centros especializados, para hacer el diagnóstico diferencial con otras enfermedades como influenza, leptospirosis, rickettsiosis, etc. que también pueden causar brotes de enfermedades febriles con hemorragia y sin ella (3-5).

\section{Bibliografía}

1. Camacho T. de la Hoz F, Cárdenas V, Sánchez C, de Calderón $L$, Pérez $L$ et al. Incomplete surveillance of a dengue 2 epidemic in Ibagué Colombia, 1995-1997. Biomédica 2004;24:174-82.

2. Organización Panamericana de la Salud. Definiciones de caso. Dengue. Boletín epidemiológico 2000;21:14-5.

3. Instituto Nacional de Salud de Colombia, Ministerio de Salud. Epidemia de influenza A/H3N2/ Beijing/32/92 en Ambalema, Tolima, 1994. Inf Quinc Epidemiol Nac 1996;1:6-8.

4. Agudelo $\mathrm{Cl}$, de la Hoz F, Olano V, Mera E. ¿Son las epidemias de dengue debidas solo a dengue? Inf Quinc Epidemiol Nac 1999;4(8).

5. De la Hoz F, Velandia MP. El papel del laboratorio en la vigilancia en salud pública. Inf Quinc Epidemiol Nac $1999 ; 4(17)$.

Fernando de la $\mathrm{Hoz}$

Departamento de Salud Pública, Universidad Nacional de Colombia, Bogotá, D.C., Colombia. 